\title{
BMJ Open Regional disparities in the intimate partner sexual violence rate against women in Paraná State, Brazil, 2009- 2014: an ecological study
}

\author{
Kátia Biagio Fontes, ${ }^{1}$ Ana Carolina Jacinto Alarcão, ${ }^{1}$ Oscar Kenji Nihei, ${ }^{2}$ \\ Sandra Marisa Pelloso, ${ }^{3}$ Luciano Andrade, ${ }^{4}$ Maria Dalva de Barros Carvalho ${ }^{5}$
}

To cite: Fontes KB, Jacinto Alarcão AC, Nihei OK, et al. Regional disparities in the intimate partner sexual violence rate against women in Paraná State, Brazil, 2009-2014: an ecological study. BMJ Open 2018;8:e018437. doi:10.1136/ bmjopen-2017-018437

- Prepublication history for this paper is available online. To view these files, please visit the journal online (http://dx.doi. org/10.1136/bmjopen-2017018437).

Received 4 July 2017

Revised 14 December 2017

Accepted 20 December 2017

Check for updates

${ }^{1}$ Health Science Center, State University of Maringa, Maringa, Brazil

${ }^{2}$ Department of Post Graduate in Public Health in Border Region and Department of Post Graduate in Studies in Society, Culture and Borders, State University of Western Paraná, Foz do Iguaçu, Brazil ${ }^{3}$ Department of Post Graduate in Health Science and Department of Post Graduate in Nursing, State University of Maringa, Maringa, Brazil

${ }^{4}$ Department of Medicine, State University of Maringa, Maringa, Brazil

${ }^{5}$ Department of Post Graduate in Health Science, State University of Maringa, Maringa, Brazil

Correspondence to Dr Kátia Biagio Fontes; katia.bf@gmail.com

\section{ABSTRACT}

Objective Evaluate disparities in a Brazilian state by conducting an analysis to determine whether socioeconomic status was associated with the reported intimate partner sexual violence (IPSV) rates against women.

Design A retrospective, ecological study.

Settings Data retrieved from the Notifiable Diseases Information System database of the Ministry of Health of Brazil.

Participants All cases of IPSV $(n=516)$ against women aged 15-49 years reported in the Notifiable Diseases Information System between 2009 and 2014.

Outcome measures The data were evaluated through an exploratory analysis of spatial data.

Results We identified a positive spatial self-correlation in the IPSV rate $(0.7105, \mathrm{P} \leq 0.001)$. Five high-high-type clusters were identified, predominantly in the Metropolitan, West, South Central, Southwest, Southeast and North Central mesoregions, with only one cluster identified in the North Pioneer mesoregion. Our findings also indicated that the associations between the IPSV rate and socioeconomic predictors (women with higher education, civil registry of legal separations, economically active women, demographic density and average female income) were significantly spatially non-stationary; thus, the regression coefficients verified that certain variables in the model were associated with the IPSV rate in some regions of the state. In addition, the geographically weighted regression (GWR) model improved the understanding of the associations between socioeconomic indicators and the IPSV notification rate, showing a better adjustment than the ordinary least square (OLS) model (OLS vs GWR model: $\mathrm{R}^{2}$ : 0.95 vs 0.99 ; Akaike information criterion: 4117.90 vs 3550.61; Moran's I: 0.0905 vs -0.0273 , respectively). Conclusions IPSV against women was heterogeneous in the state of Paraná. The GWR model showed a better fit and enabled the analysis of the distribution of each indicator in the state, which demonstrated the utility of this model for the study of IPSV dynamics and the indication of local determinants of IPSV notification rates.

\section{INTRODUCTION}

Intimate partner violence is the most common type of violence against women
Strengths and limitations of this study

- The ecological design of the study allowed the identification of geographical areas and clusters in Paraná state with higher intimate partner sexual violence against women notification rates.

- At the population level, the study design also enabled identification of the social and economic factors associated with higher intimate partner sexual violence against women notification rates.

- As a limitation, the study findings are based on data from sexual violence notifications, which may reflect only a portion of the cases involving intimate partner sexual violence in Paraná state, since this crime is frequently undernotified.

- We could not infer causality in this study and could only determine associations of the significant variables.

and is perpetrated by a partner or former partner. Sexual violence and intimate partner violence are major public health problems that occur worldwide and can damage the physical, sexual, reproductive, emotional, mental and social health of the victim and his/her family. ${ }^{1}$

According to global estimates by WHO, one in three women has suffered sexual violence, ${ }^{1}$ the majority of which occurs in the domestic environment, corresponding to 12 million people annually. ${ }^{2}$ In Brazil, sexual violence against women has been positively associated with a low family income, experience of sexual violence in childhood, ${ }^{3}$ and development of post-traumatic stress symptoms. ${ }^{4}$

Although frequent, estimating the magnitude and consequences of sexual violence is challenging because many women are silenced by shame, discrimination and fear of partner reprisals. ${ }^{5}$

A 2005 study conducted by WHO in 10 countries showed that the rate of intimate partner sexual violence (IPSV) among 


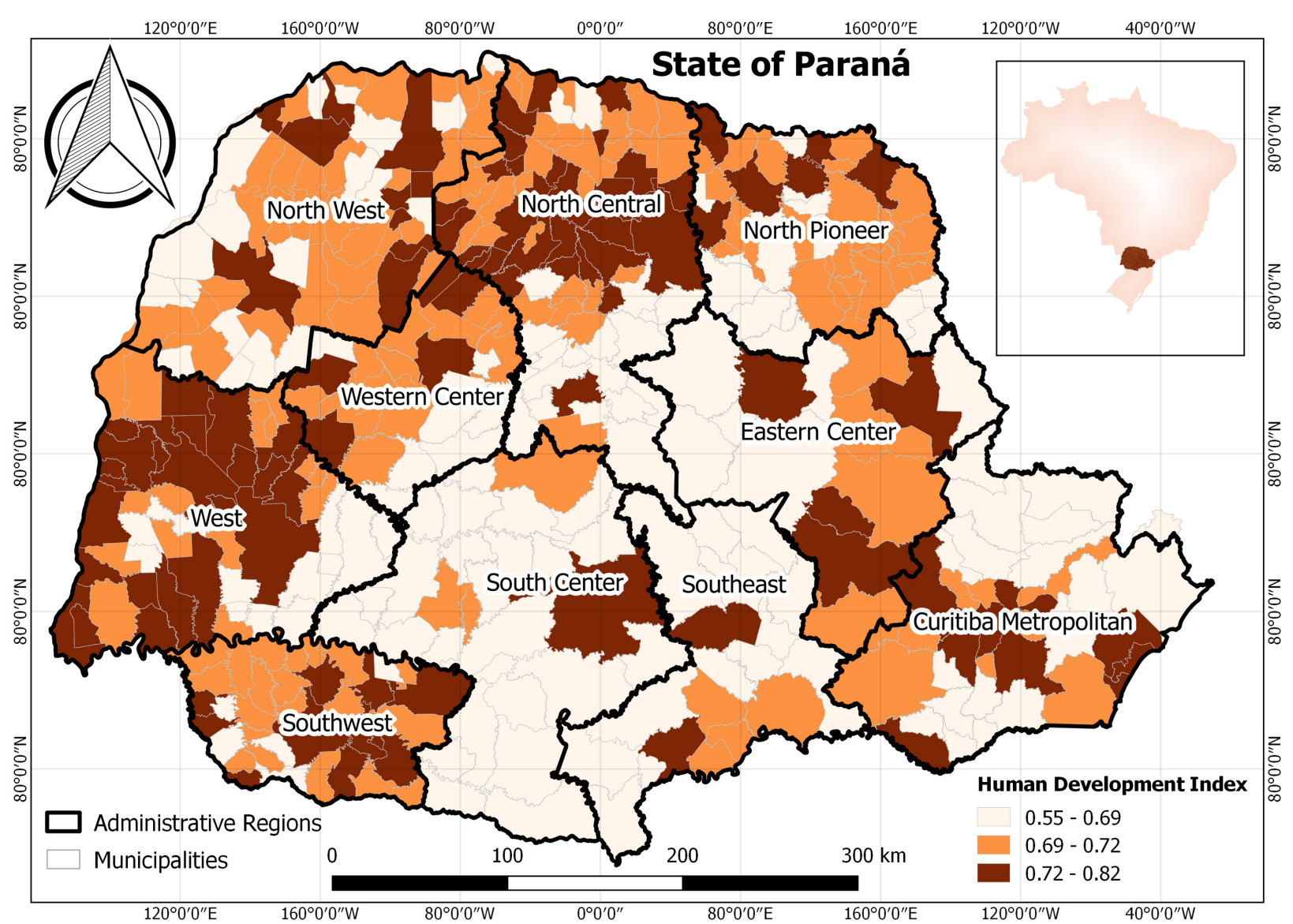

Figure 1 State of Paraná and the municipality Human Development Index levels.

women aged 15-49 years ranged from $6.2 \%$ in Japan to $58.6 \%$ in Ethiopia. ${ }^{1}$

Recent studies performed in public health services in Brazil have reported IPSV rates of $20.3 \%$ in women aged $15-49$ years in the Southeast of the country ${ }^{6}$ and $5.7 \%$ in women aged 20-59 years in the state of Espirito Santo. ${ }^{4}$ Another study conducted in the city of São Paulo and 15 municipalities in the state of Pernambuco showed rates of $10.1 \%$ and $14.3 \%$, respectively. ${ }^{7}$

Notification of violence against women remains a new process in Brazil and is conducted at health units. However, the woman is responsible for the decision to report the violence, to submit herself to medical examinations and even to perform an abortion if conception results from sexual violence. ${ }^{8}$

Data from the Ministry of Health of Brazil on IPSV notification rates involving women showed that the Southern region presented the second highest rate of this type of violence between 2009 and 2014. Among the states in the Southern region, Paraná ranked first in this category (17.6/100 000 women) with a figure higher than the national rate (10.4/100 000 women). ${ }^{9}$

Geospatial studies conducted in Brazil have identified areas that are vulnerable to domestic violence against women in municipalities in the states of Paraiba ${ }^{10}$ and Rondonia, ${ }^{11}$ where networks of social and economic relationships may favour or curb its occurrence. ${ }^{11}$ Studies investigating IPSV against women are scarce in the scientific literature, and to the best of our knowledge, no study has analysed the spatial distribution of IPSV against women and the associated geospatial indicators.

Determining the spatial distribution of IPSV against women and the socioeconomic indicators involved in this type of violence is the first step in identifying geographically vulnerable areas and priorities for the establishment of public policy investment and constructing instruments to prevent, identify and contain this type of violence.

This study evaluates regional disparities in Paraná state and performs analyses to determine whether socioeconomic status is associated with the sexual violence by intimate partner notification rates for women aged 15-49 years in the state of Paraná, Brazil, from 2009 to 2014.

\section{METHODS}

\section{Study design and location}

This study was an ecological, retrospective study based on secondary data for the IPSV notification rates that used geospatial analysis techniques.

Paraná state is located in Southern Brazil (latitude coordinates $22^{\circ} 30^{\prime} 58^{\prime \prime}$ and $26^{\circ} 43^{\prime} 00^{\prime \prime}$ and longitude coordinates $48^{\circ} 05^{\prime} 37^{\prime \prime}$ and $54^{\circ} 37^{\prime} 08^{\prime \prime}$ ) and covers an area of $199880 \mathrm{~km}^{2}$. This state is bordered by Paraguay and Argentina and the states of São Paulo, Mato Grosso do Sul and Santa Catarina. Paraná contains 10 geographical mesoregions subdivided into 399 municipalities (figure 1). 


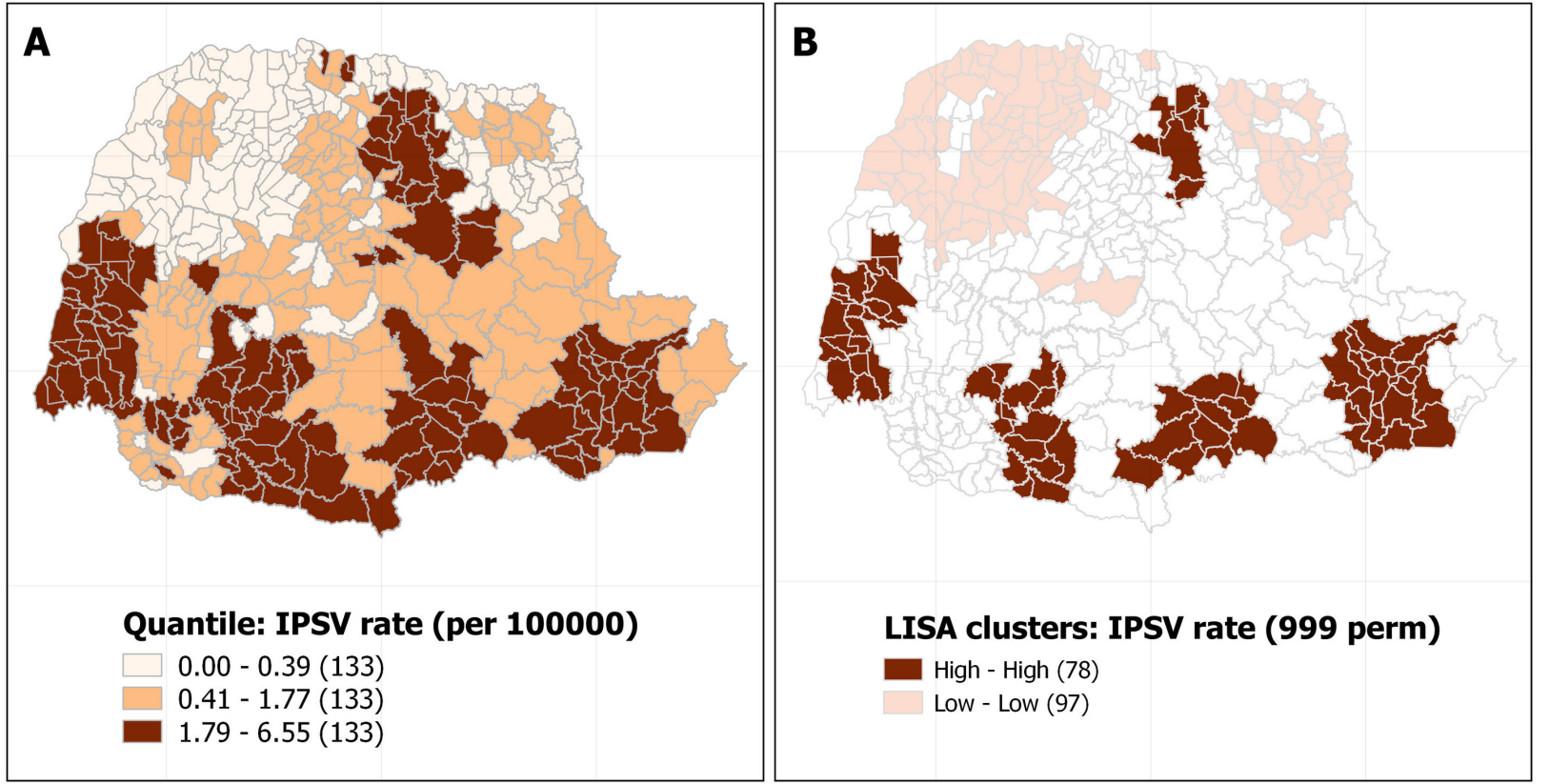

Figure 2 (A) Spatial distribution of weighted intimate partner sexual violence (IPSV) notification rates/100 000 women in Paraná, Brazil, from 2009 to 2014. (B) Local indicators of spatial association (LISA) univariate analysis: formation of cluster types according to the IPSV notification rate/100 000 women in Paraná, Brazil, from 2009 to 2014.

According to the 2010 Brazilian Census, Paraná state includes 10444526 inhabitants who live predominantly in urban areas $(85.3 \%) .{ }^{12}$ The state of Paraná is ranked fifth in the Human Development Index (HDI=0.749) and is the fifth state ranked according to the economy in Brazil. ${ }^{13}$ Figure 1 shows the distribution of the HDI in the state of Paraná and its administrative regions. ${ }^{14}$ Notably, the economic development of the state is uneven. The Northern and Western areas of the state are more developed (with more cities with higher HDIs), as is the metropolitan area of the state capital (Curitiba). The centre and Southern areas are less developed than the rest of the state. This disparity is important for understanding the distribution of health outcomes, such as IPSV.

\section{Data source}

For this study, data for the number of notifications of IPSV (sex partners, including a spouse, ex-spouse, boyfriend, ex-boyfriend, girlfriend and ex-girlfriend) for both genders against women aged 15-49 years old per residence in the 399 municipalities of the state from 2009 to 2014 were obtained from the Notifiable Diseases Information System ${ }^{9}$ of the Ministry of Health. Since 2003, notification of violence against women has been compulsory in health services in Brazil. ${ }^{15}$

The population of each municipality according to age group was obtained from the Brazilian Institute of Geography and Statistics (IBGE). ${ }^{12}$ Five municipal socioeconomic and demographic indicators based on the last demographic census (2010) were formulated as follows: 'population density (inhabit $/ \mathrm{km}^{2}$ )' was obtained from the Paraná Institute of Economic and Social Development, ${ }^{9}$ whereas data on the "civil registry of legal separations $(\%)$ ', 'women with higher education (\%)', 'economically active women (\%)' and 'average female income' were obtained from the IBGE. ${ }^{12}$

\section{Spatial analysis}

\section{Spatial autocorrelation}

We performed an exploratory analysis of spatial data to determine the spatial self-correlation measures of the IPSV rates. First, to minimise variation in the IPSV notification rates by city and the possible random fluctuations derived from the analysis of small populations, the empirical Bayesian estimator was used in the queen weights matrix in GeoDa, which considers all neighbourhoods that have a common frontier. ${ }^{1617}$

This estimator calculates a weighted notification rate by considering regional variances and therefore allowing comparisons between different populations. In the state of Paraná, 364 (91.2\%) municipalities have less than 20000 inhabitants; thus, most cities are small, and the distribution of the phenomenon is heterogeneous. Furthermore, under-reporting of IPSV is an important problem, particularly in small cities. ${ }^{18}$

Using the Global Moran's I statistic, spatial self-correlation was calculated based on the IPSV notification rate per 100000 women for each municipality. Moran's I varies between -1 and +1 . Values greater or less than the expected Moran's I value $(\mathrm{E}(\mathrm{I})=-1 /(\mathrm{n}-1))$ indicate a positive or negative self-correlation, respectively. A positive spatial self-correlation indicates that neighbouring areas present values similar to those of the analysed area, and a negative spatial self-correlation indicates that neighbouring areas present values different from those of the analysed area. A Moran's I value of 0 (zero) represents the hypothesis of spatial independence. ${ }^{19}$ 
Table 1 Comparison of the OLS and GWR multivariate spatial regression models, Paraná, Brazil, 2009-2014

\begin{tabular}{llll}
\hline & \multicolumn{2}{c}{ OLS } & \multicolumn{1}{c}{ GWR } \\
\cline { 2 - 3 } Variables $^{*}$ & $\begin{array}{l}\text { Estimate } \\
\text { (SE) }\end{array}$ & $\mathbf{t}$ (Estimate/SE) & $\begin{array}{l}\text { Estimate mean } \\
\text { (Estimate SD) }\end{array}$ \\
\hline Pred 1 & -0.000112 & -0.888274 & 0.000068 \\
& $(0.000126)$ & & $(0.001093)$ \\
Pred 2 & 0.008735 & 28.1311681 & 0.002573 \\
& $(0.000310)$ & & $(0.004972)$ \\
Pred 3 & -0.014992 & -8.564911 & -0.000450 \\
& $(0.001750)$ & & $(0.009987)$ \\
Pred 4 & -0.096828 & -4.832063 & -0.001957 \\
& $(0.020039)$ & & $(0.061672)$ \\
Pred 5 & -0.000261 & -1.163508 & 0.000066 \\
& $(0.000224)$ & & $(0.000298)$ \\
AlC & 411.790 & & 3550.61 \\
Moran's I & 0.0905 & & -0.0273 \\
Adjusted R & 0.95 & & 0.99 \\
\hline
\end{tabular}

*Pred 1: demographic density (inhabitants $/ \mathrm{km}^{2}$ ); Pred 2: economically active women (\%); Pred 3: civil registry of legal separations (\%); Pred 4: women with higher education (\%); Pred 5: average female income.

AIC, Akaike information criterion; GWR, geographically weighted regression; OLS, ordinary least square regression.

The Global Moran's I can hide local patterns of spatial association, since a negative Global Moran's I values does not necessarily indicate the absence of a spatial correlation on a local level. To avoid this limitation, local indicators of spatial association were applied to identify significant cluster formation, which was visualised in choropleth maps. Spatial clusters were categorised according to the patterns and characteristics of the adjacent districts. High-high $(\mathrm{HH})$ clusters are a set of districts with high rates that are surrounded by other districts with high reporting rates. Low-low (LL) clusters are groups of districts with low rates surrounded by low rate districts. The global and local spatial autocorrelation coefficients were considered significant when $\mathrm{P}<0.05$.

\section{Spatial regression}

Although Global and Local Moran's I are well-known statistical techniques, they are univariate and do not consider multivariate effects. Thus, we chose to use regression models with and without control for spatial dependence.

Therefore, the ordinary least square regression (OLS) and geographically weighted regression (GWR) models were used to explore the relationships between the IPSV notification rates and independent variables.

\section{Ordinary least squares}

In the OLS regression analysis, we included all predictors within our secondary database that were previously shown to be associated with IPSV. To improve multicollinearity and the model's performance, we iteratively conducted a sensitivity analysis and chose the model with the best
Akaike information criterion (AIC)/Bayesian information criterion values and the lowest multicollinearity. The variables entered in the model were 'women with higher education (\%)', civil registry of legal separations (\%)', 'economically active-busy women (\%)', 'population density (inhabitants $/ \mathrm{km}^{2}$ )' and 'average female income'.

In sequence, residuals from the global OLS model were analysed for spatial self-correlation using Moran's I to evaluate the extent of the outcome that could be explained by the spatial component after modelling for predictors. The increase was not very large when we compared the OLS and spatial lag models. Thus, we chose to keep the classical regression.

\section{Geographically weighted regression}

Additionally, since the dependent variable presented strong (univariate) positive spatial self-correlation, we chose to use GWR to identify possible local associations and to demonstrate the spatial effect of the multivariate model. Thus, the coefficients of each predictor that were significant in the overall model were plotted to determine the impact of space on the outcome.

Compared with the OLS model, which presents constant regression coefficients in relation to the geographical space (stationarity), the coefficients in the GWR model are estimated locally from analysis of the spatial variability of the results in each area, which enables verification of the presence of spatial non-stationarity (ie, whether the relationships between regression variables vary in relation to the geographical space)..$^{20}$ Consequently, the GWR model generates a set of local linear regression models rather than a global model with estimates for each sample in space. ${ }^{21}$ The performance of the GWR model was evaluated based on the adjusted $\mathrm{R}^{2}$ indicators, AIC parameters and Moran's I of the residues of both models.

The spatial self-correlation and the OLS model were processed using the GeoDa software V.1.10.0.8 (Spatial Analysis Laboratory, University of Illinois at Urbana-Champaign, Urbana, Illinois , USA) ${ }^{17}$ whereas the GWR model was implemented by GWR V.4.0. ${ }^{22}$ Choropleth maps were generated using the QGIS V.2.14 software. ${ }^{23}$

\section{Ethical notes}

This study did not require ethical approval and consent from each individual since the data used were secondary and were available from government databases of online data. However, this study followed the national guidelines for research with human subjects. ${ }^{24}$

\section{RESULTS}

A total of 516 IPSV reports against women aged 15-49 years were recorded from 2009 to 2014. A mean annual rate of 2.93/100 000 women with IPSV against women occurred during the period, with municipal rates ranging from 0 to 23.3/100 000 women. According to the race/ colour/ethnicity of the victims, the predominantly affected women were white (67.8\%) and brown (20.0\%). 

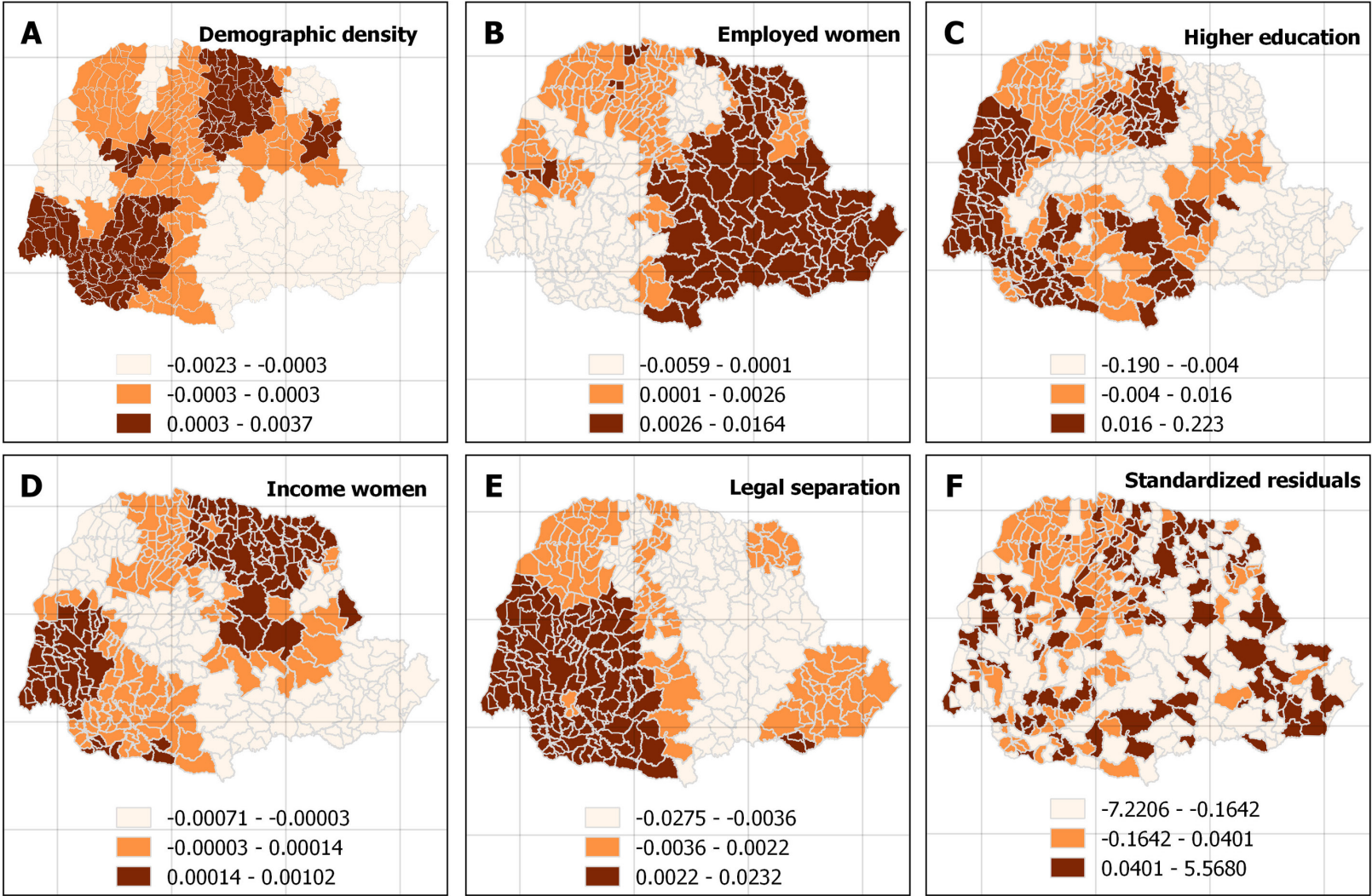

Figure 3 Map of waste/significant variables within the geographically weighted regression model, separated by degree of association. (A) Spatial distribution of the demographic density (inhabitants $/ \mathrm{km}^{2}$ ). (B) Spatial distribution of economically active women (\%). (C) Spatial distribution of women with higher education (\%). (D) Spatial distribution of the average female income. (E) Spatial distribution of the civil registry of legal separations (\%). (F) Spatial distribution of the standardised residuals.

The predominant age groups were $30-39$ years $(34.3 \%)$ and $20-29$ years $(28.5 \%)$.

Regarding schooling, incomplete primary education $(37.6 \%)$, complete secondary school $(16.3 \%)$ and incomplete secondary school (12.2\%) predominated. Only $6.4 \%$ of the subjects reported having a higher education. The main aggressor was the spouse $(56.4 \%)$, followed by a former spouse $(22.7 \%)$, former boyfriend $(10.7 \%)$ and boyfriend/girlfriend (10.3\%). The likely aggressor had suspected alcohol use in $52.1 \%$ of the cases. According to location, the violence occurred predominantly in the home $(83.5 \%)$ or in a public pathway $(8.1 \%)$. The majority of the cases were referred to as repetitive violence $(69.4 \%)$. The assessed women were predominantly referred to an outpatient clinic $(51.2 \%)$ or hospital for admission (7.9\%). Occurrences evolved to evasion/ escape or death in $1 \%$ and $0.6 \%$ of cases, respectively. The gender of the aggressor could not be identified due to the non-existence of this variable in the database.

Figure 2A shows the spatial distribution of the weighted rate of IPSV notifications classified according to the intensity grade. Of the 399 cities in the state of Paraná, rates greater than 1.79-6.55 were identified in $33.3 \%$ of the municipalities and were mainly distributed in the Metropolitan, West, South Central, Southwest, Southeast, North Central and North Pioneer mesoregions.
The IPSV notification rates presented positive spatial autocorrelation (Global Moran's I $=0.710519$ ), showing that the IPSV notification rates in municipalities influenced this same rate in the neighbouring municipalities.

Figure 2B shows the spatial autocorrelation using the formation of the types of clusters presented in the state of Paraná according to the IPSV rate. Five HH clusters were identified, involving $19.5 \%$ of the state's municipalities. Four clusters were located in the Southern region of the state, involving the Metropolitan, West, Southeast, South Center and Southwest mesoregions. Only one cluster was identified in the North mesoregion. The largest HH cluster encompassed municipalities located predominantly in the Metropolitan mesoregion.

As indicated in figure 1, further analysis of the data presented in figure 2B showed that although some municipalities involved in $\mathrm{HH}$ cluster formation presented high HDIs (0.73-0.82), the clusters predominantly presented municipalities with lower HDIs. Conversely, municipalities with high HDIs predominately displayed a LL pattern cluster, particularly in the North mesoregion.

Classical and OLS regression models (GWR) were used to identify the socioeconomic indicators most associated with the sites with the highest IPSV reporting rates.

According to these models, the indicators 'civil registry of legal separations', 'economically active women', 
'demographic density' and 'average female income' were significant. The indicator 'women with higher education' was significant only in the GWR model. The correlation with the IPSV notification rate was negative in both models for 'women with higher education' and 'civil registration of legal separations' and positive for 'economically active women'. However, the indicators 'demographic density' and 'average female income' presented different results (negative or positive correlations) according to the model used.

Compared with the OLS model results, the GWR model improved understanding of the associations between socioeconomic indicators and the IPSV reporting rate. The adjusted $R^{2}$ coefficient increased from 0.95 to 0.99 , the AIC decreased from 4117.90 to 3550.61 and Moran's I of the residues increased from 0.0905 to -0.0273 , showing a better fit of the GWR model (table 1).

Figure 3 shows the contribution of different indicators to the variation in the IPSV notification rate. The results were as follows: (1) the population density rate increased mainly in the Western mesoregion (figure 3A); (2) the rate of 'economically active women' increased in the Southeast Metropolitan, Eastern Centre and North Pioneer mesoregions (figure 3B); (3) the rate of 'women with higher education' decreased in the Western, Northwest, North central, Southwest, South central and Southeast mesoregions (figure 3C); (4) the rate of 'average female income' increased in the Western, Northern Pioneer, Central North and Eastern Central regions (figure 3D) and (5) the rate of 'civil registry of legal separations' decreased with the IPSV notification rate (figure 3E). The residuals of the model presented a random distribution throughout the state (figure 3F).

\section{DISCUSSION}

This study is the first to analyse the spatial distribution of the IPSV reporting rates and associated municipal indicators. The use of spatial analysis successfully identified clusters of IPSV rates against women and demonstrated that the phenomenon was heterogeneous in the state, with HH clusters distributed mainly in the Metropolitan, West, Center South, Southwest, Southeast and North central mesoregions. We identified important socioeconomic indicators associated with the IPSV reporting rates against women, which could contribute to understanding the phenomenon; these rates will serve as a subsidy for the identification of vulnerable populations and the elaboration and implementation of policies for the prevention and control of this type of grievance.

Demographic density has been shown to increase the likelihood of IPSV reporting rates. The positive association between demographic density and homicide has been previously demonstrated in this country ${ }^{25}{ }^{26}$; however, other studies did not report this association. ${ }^{27-29}$ In our study, mesoregions with high HDI values, such as the Metropolitan, North Central and West, were involved in the $\mathrm{HH}$ clusters.
Our findings showed that the proportion of women with a higher education who were judicially separated contributed to the decrease in IPSV. Previous studies have shown that women with higher schooling and incomes are more likely to leave violent marriages. ${ }^{30}$

The average female income and the proportion of economically active women influenced the increase in the reports of IPSV, which contrasted with the results of previous studies. Low financial autonomy has been presented as a risk factor for sexual violence by intimate partners. ${ }^{31}{ }^{32}$ Conversely, financial independence is a protective factor for physical and emotional violence. ${ }^{31}$ Recently, a decrease in the wage gap between men and women in the USA has led to a reduction in violence against women. ${ }^{33}$ In 2000, the United Nations (UN) integrated the millennial development objectives for the promotion of equality between the genders and the autonomy of women. ${ }^{34}$ The UN has published a report showing progress in this area.

In the 20th century, after the entry of women into the labour market, the family system in Brazil experienced a transition process in which male control based on the role as provider was held in check consistent with the occurrence of violence, including sexual violence. ${ }^{35}$

Acceptance of beatings by the wife has been presented as a risk factor for sexual violence. ${ }^{31}$ Daughters with parents involved in marital violence are more likely to suffer intimate partner violence, ${ }^{31} 3637$ as are the offspring of offending abuse, ${ }^{32}$ suggesting that violence can spread for generations. This context may prevent women from verbalising complaints of violence to health professionals. ${ }^{38}$

Our regression analysis is based on city indicators and IPSV report rates available on national databases. Reliance on these data could limit the impact of this study. However, we have used the Bayesian estimator to minimise any inconsistencies. The reporting of violence against women is a new process in Brazil, and under-reporting remains a problem, either because of a lack of training and/or misunderstanding of its importance by health professionals ${ }^{18}$ or because the omission of victims. ${ }^{38}$ This fact can account for only some of the cases involving the problem of IPSV in the state of Paraná, resulting in a limitation of this study. However, identifying the panorama of IPSV in the regions and the municipal indicators involved in this type of injury is the first step in planning or even strengthening strategies of control and prevention.

Our study was developed in a Brazilian state with a high HDI, similar to those of developed countries, which allows generalising the results for similar areas, but mainly for those areas with economic and social disparities.

The reporting of violence against women is a new process in Brazil, and under-reporting remains a problem either due to lack of training and/or misunderstanding of its importance by health professionals ${ }^{18}$ or even omission by victims. ${ }^{38}$ However, identifying the panorama of IPSV in the regions and the municipal 
indicators involved in this type of injury are the first steps in planning or even strengthening control and prevention strategies.

In 2003, the Brazilian government formulated a National Plan of Policies for Women, ${ }^{39}$ which among other actions had the purpose of implementing a National Policy to Combat Violence against women and guaranteeing specialised services and a humanised care network. $^{40}$

In 2015, the state of Paraná launched a protocol that unified care for people who suffered from some type of sexual violence outside the home environment. ${ }^{41}$ However, most health programmes and services do not have protocols for domestic violence cases and sexual violence against women by an intimate partner at present. $^{35}$

Since most municipalities in the state do not have all the reference services of the network to combat violence against women (eg, specialised police stations and shelter houses), expansion of human resources and structures has become essential. Moreover, since violence against women is a paradigm that can propagate for generations, clarification for and guidance of women, children and adolescents should be a priority.

\section{CONCLUSIONS}

IPSV against women was heterogeneous in every state and was distributed throughout the Metropolitan, West, Central, Southwest, Southeast and Central North mesoregions. The maps generated by the GWR model were used to analyse the distribution of each indicator in the state, demonstrating the utility of this model in the study of IPSV dynamics and the identification of local determinants of the IPSV notification rates. The identification of areas vulnerable to IPSV and their respective determinants will serve to improve prevention strategies and strengthen public policies aimed to prevent and control IPSV.

Contributors KBF, ACJA, LA and MDdBC were involved in conceptualisation; KBF and $L A$ were involved in the formal analysis; KBF, ACJA, OKN, SMP and MDdBC were involved in the investigation; KBF, $L A$ and $M D d B C$ were involved in the methodology; KBF and MDdBC were involved in project administration; KBF, ACJA, OKN, SMP, LA and MDdBC were involved in resources; LA was involved in the statistical analysis; MDdBC was involved in supervision and KBF, ACJA, OKN, SMP, $\mathrm{LA}$ and MDdBC were involved in writing (original draft, review and editing).

Funding This research received no specific grant from any funding agency in the public, commercial or not-for-profit sectors.

Competing interests None declared.

Patient consent Not required.

Provenance and peer review Not commissioned; externally peer reviewed.

Data sharing statement No additional data are available.

Open Access This is an Open Access article distributed in accordance with the Creative Commons Attribution Non Commercial (CC BY-NC 4.0) license, which permits others to distribute, remix, adapt, build upon this work non-commercially, and license their derivative works on different terms, provided the original work is properly cited and the use is non-commercial. See: http://creativecommons.org/ licenses/by-nc/4.0/ (c) Article author(s) (or their employer(s) unless otherwise stated in the text of the article) 2018. All rights reserved. No commercial use is permitted unless otherwise expressly granted.

\section{REFERENCES}

1. World Health Organization. Prevenção da violência sexual e da violência pelo parceiro íntimo contra a mulher: ação e produção de evidência. 2010 https://goo.gl/Hc3rme (accessed 25 Apr 2017).

2. Brasil. Ministério da Saúde. Secretaria de Atenção à Saúde. Departamento de Ações Programáticas Estratégicas. Área Técnica de Saúde da Mulher. Prevenção e Tratamento dos Agravos Resultantes da Violência Sexual contra Mulheres e Adolescentes: norma técnica. Brasília: Ministério da Saúde, 2012:126. https://goo. gl/hvwyCQ.

3. Machado CL, de Azevedo RC, Facuri CO, et al. Posttraumatic stress disorder, depression, and hopelessness in women who are victims of sexual violence. Int J Gynaecol Obstet 2011;113:58-62.

4. Leite FMC, Amorim MHC, Wehrmeister FC, et al. Violence against women, Espírito Santo, Brazil. Rev Saude Publica 2017;51:33.

5. World Health Organization. World report on violence and health: prevention. Genebra: World Health Organization, 2002. (accessed 23 Oct 2017). https://goo.gl/nxAnbb.

6. Barros CR, Schraiber LB. Intimate partner violence reported by female and male users of healthcare units. Rev Saude Publica 2017;51:7.

7. Schraiber LB, D'Oliveira AF, França-Junior I, et al. [Prevalence of intimate partner violence against women in regions of Brazil]. Rev Saude Publica 2007;41:797-807.

8. Paiva EA, da S, das N, et al. Violence against women: analysis of the reports made in the health sector: Brazil, 2011. Divulg. saúde debate 2014;52:72-87 https://goo.gl/7f8QKa.

9. Brazil. Ministry of Health. Department of the Unified Health System (Datasus) Datasus. Informações de Saúde (TABNET). Epidemiológicas e Morbidade. Doenças e Agravos de Notificação (SINAN). Violência doméstica, sexual e/ou outras violências. http://www2.datasus.gov.br/DATASUS/index.php?area=0203\&id= 29892332\&VObj=http://tabnet.datasus.gov.br/cgi/deftohtm.exe? sinannet/cnv/viole (accessed 23 Oct 2017).

10. Lucena KD, Silva AT, Moraes RM, et al. [Spatial analysis of domestic violence against women from 2002 to 2005 in João Pessoa, Paraíba State, Brazil]. Cad Saude Publica 2012;28:1111-21.

11. Ribeiro MIC, Silva M das GSN. violence, Vulnerability and Social and Spacial inequality: an analysis of the difficulties faced by women who are victims of domestic violence in the urban area of Porto Velho RO. Revista Latino-americana de Geografia e Gênero 2015;6:92-104 https://goo.gl/RP5TLi.

12. Brazilian Institute of Geography and Statistics. Censo Demográfico, 2010. https://goo.gl/rRfzZC. (accessed 11 may 2017).

13. Paraná. Parana Institute of Economic and Social Development Ipardes. Base de Dados do Estado - BDEweb http:// www.ipardes.pr.gov.br/imp/index.php (accessed 25 Apr 2017).

14. Programa das Nações Unidas para o Desenvolvimento.IDH. Ranking IDHM Municípios 2010 https://goo.gl/M67h3t (accessed 23 Oct 2017).

15. Brasil. Ministério da Saúde. Secretaria de Vigilância em Saúde. Departamento de Vigilância de Doenças e Agravos Não Transmissíveis e Promoção da Saúde.Viva: instrutivo. Notificação de violência interpessoal e autoprovocada. Brasília: Ministério da Saúde, 2016. 92. https://goo.gl/ivALfB.

16. Santos AE, Rodrigues AL, Lopes DL. Estimadores bayesianos empíricos para análise espacial das taxas de mortalidade. Em: VII Simpósio Brasileiro de Geoinformação. Campos do Jordão-SP 2005 https://goo.gl/aKiaWU (accessed 23 Oct 2017).

17. Anselin L, Syabri I, Kho Y. GeoDa: An Introduction to Spatial Data Analysis. Geogr Anal 2006;38:5-22.

18. de Sousa MH, Bento SF, Osis MJ, et al. Filling out the compulsory notification in health services that care for women who suffer from sexual violence. Rev Bras Epidemiol 2015;18:94-107.

19. Anselin L. Interactive techniques and exploratory spatial analysis. In: Longley PA, Goodchild MF, Maguire DJ, Rhind DW, eds. Geographical information systems: principles, techniques, management and applications. New York: Wiley, 1999:253-65. https://goo.gl/ymGAJy (accessed 11 may 2017).

20. Oliveira S, Pereira JMC, San-Miguel-Ayanz J, et al. Exploring the spatial patterns of fire density in Southern Europe using Geographically Weighted Regression. Appl Geogr 2014;51:143-57.

21. Ndiath MM, Cisse B, Ndiaye JL, et al. Application of geographicallyweighted regression analysis to assess risk factors for malaria hotspots in Keur Soce health and demographic surveillance site. Malar J 2015;14:463. 
22. Nakaya T, Fotheringham AS, Charlton M, et al. Semiparametric geographically weighted generalised linear modelling in GWR 4.0. In: Lees BG, Laffan SW, eds. 10th International Conference on GeoComputation, 30th November-2nd. Sydney: UNSW, 2009. https://goo.gl/bDdx6h (accessed 23 Oct 2017).

23. QGIS Development Team, 2017. QGIS Geographic Information System. Open Source Geospatial Foundation Project. 2017 http:// qgis.osgeo.org (accessed 23 Oct 2017).

24. Brasil.Conselho Nacional de Saúde. Ética na Pesquisa na área de Ciências Humanas e Sociais. Resolução $n^{\circ} 510$ de 07 de abril de. $2016 \mathrm{https}: / /$ goo.gl/8JGJij (accessed 23 Oct 2017).

25. Menezes T, Silveira-Neto R, Monteiro C, et al. Spatial correlation between homicide rates and inequality: Evidence from urban neighborhoods. Econ Lett 2013;120:97-9.

26. Szwarcwald CL, Bastos FI, Viacava F, et al. Income inequality and homicide rates in Rio de Janeiro, Brazil. Am J Public Health 1999;89:845-50.

27. Leites GT, Meneghel SN, Hirakata VN. Female homicide in Rio Grande do Sul, Brazil. Female homicide in Rio Grande do Sul, Brazil. Rev. bras. Epidemiol 2014;17:642-53.

28. Gawryszewski VP, Costa LS. [Social inequality and homicide rates in Sao Paulo City, Brazil]. Rev Saude Publica 2005;39:191197.

29. Lima MLC de, Ximenes RA de A, Souza ER de, et al. Spatial analysis of socioeconomic determinants of homicide in Brazil. Rev. Saúde Pública 2005;39:176-82.

30. Kreager DA, Felson RB, Warner C, et al. Women's Education, Marital Violence, and Divorce: A Social Exchange Perspective. J Marriage Fam 2013;75:565-81.

31. Gage AJ. Women's experience of intimate partner violence in Haiti. Soc Sci Med 2005;61:343-64.
32. Tu X, Lou C. Risk factors associated with current intimate partner violence at individual and relationship levels: a cross-sectional study among married rural migrant women in Shanghai, China. BMJ Open 2017;7:e012264.

33. Aizer A. The gender wage gap and domestic violence. Am Econ Rev 2010;100:1847-59.

34. United Nations. The millennium development goals report 2015 http://www.un.org/millenniumgoals/2015_MDG_Report/pdf/ MDG\%202015\%20rev\%20(July\%201).pdf (accessed 25 Apr 2017).

35. Dantas-Berger SM, Giffin K. Violence in conjugal relations: concealing and taking sexual violence for granted? Cad. Saúde Pública 2005;21:417-25.

36. Jewkes R, Levin J, Penn-Kekana L. Risk factors for domestic violence: findings from a South African cross-sectional study. Soc Sci Med 2002;55:1603-17.

37. d'Oliveira AF, Schraiber LB, França-Junior I, et al. [Factors associated with intimate partner violence against Brazilian women]. Rev Saude Publica 2009;43:299-311.

38. Kronbauer JF, Meneghel SN. [Profile of gender violence by intimate partners]. Rev Saude Publica 2005;39:695-701.

39. Brasil. Presidência da República. Secretaria Especial de políticas para as mulheres. Plano Nacional de Políticas para as Mulheres. Brasilia 2006:26 https://goo.gl/mbsSu7

40. Brasil. Presidência da República. Secretaria de Políticas para as Mulheres. Política Nacional de Enfrentamento à Violência contra as Mulheres. Brasilia. 2011:46 https://goo.gl/BMXPAf

41. Paraná.Secretário de Estado da Saúde. Protocolo para o Atendimento às Pessoas em Situação de Violência sexual. Curitiba 2015 https://goo.gl/8H3M9r (accessed 23 Oct 2017). 